\title{
Violência contra mulheres: o perfil da vítima e do agressor em São Luís-MA
}

\author{
Violence against women: the profile of the victim and the aggressor in São Luís-MA
}

Violencia contra la mujer: el perfil de la víctima y el agresor en São Luís-MA

Amanda Ribeiro Bezerra* $₫(\mathbb{D}$, Zulimar Márita Ribeiro Rodrigues $\square(\mathbb{D}$

Departamento de Geociências, Programa de Pós-Graduação em Geografia, Universidade Federal do Maranhão, São Luís, Maranhão, Brasil

Recebido (Received): 28/10/2020

E-mail: zulimar.marita@ufma.br

Aceito (Accepted): 18/06/2021

*E-mail para correspondência: amandaribeirob@hotmail.com

Resumo: A pesquisa analisou a violência contra a mulher em São Luís-MA, traçando o perfil da vítima e agressor; e mapeou a distribuição espacial das agressões, através da emissão de medidas protetivas pela justiça. Utilizaram-se metodologias apoiadas no materialismo histórico e dialético, nas discussões de gênero e nas desigualdades intraurbanas. Foram empregados dados secundários, dos relatórios denominados "Pesquisa Social", publicados entre 2009 e 2019, pelas $1^{\text {a }}$ e $2^{\text {a }}$ Varas Especiais de Violência Doméstica e Familiar contra a Mulher da Comarca de São Luís. O perfil da mulher vítima de violência doméstica, na sua maioria, são solteiras e/ou casadas, com idades que variam entre 26 e 43 anos, mãe de um ou mais filhos e sem renda fixa. Os agressores têm entre 26 e 34 anos, com diferentes profissões. Os atos violentos foram praticados majoritariamente por indivíduos que não têm mais relações afetivas com as vítimas e entre as motivações para a violência destacam-se o inconformismo com o fim da relação, ciúmes, dentre outros. A distribuição espacial da violência contra a mulher é heterogênea na escala intraurbana da capital maranhense, revelando certa desigualdade social, pois, a maioria das medidas protetivas, foi concedida para mulheres que habitam bairros pobres e periféricos, mas isso não quer dizer que a violência não esteja nos bairros com população de maior renda. Mesmo com o crescimento do acesso aos serviços especializados de denúncia e proteção às vítimas de violência de gênero, considera-se que ainda estão mal distribuídos pela cidade.

Palavras-chaves: Desigualdades Intraurbanas; Perfil Socioeconômico; Geografias Feministas.

Abstract: The research analyzed violence against women in São Luís-MA, tracing the profile of the victim and aggressor; and mapped the spatial distribution of the aggressions, through the issuance of protective measures by justice. Methodologies based on historical and dialectical materialism, gender discussions and intra-urban inequalities were used. Secondary data were used, from reports called "Social Research", published between 2009 and 2019, by the 1st and 2nd Special Courts of Domestic and Family Violence against Women in the District of São Luís. The profile of women who are victims of domestic violence, mostly, are single and/or married, aged between 26 and 43 years old, mother of one or more children and without fixed income. The aggressors are between 26 and 34 years old, with different professions. Violent acts were practiced mostly by individuals who no longer have affective relationships with the victims and among the motivations for violence the non-conformity with the end of the relationship, jealousy, among others stands out. The spatial distribution of violence against women is heterogeneous in the intra-urban scale of the capital of Maranhão, revealing a certain social inequality, since most protective measures were granted to women living in poor and peripheral neighborhoods, but this does not mean that violence does not exist in the neighborhoods with the highest income population. Even with the increase in access to specialized services for reporting and protecting victims of gender violence, it is considered that they are still poorly distributed throughout the city.

Keywords: Intra-urban inequalities; Socioeconomic Profile; Feminist Geography.

Resumen: La investigación analizó la violencia contra las mujeres en São Luís-MA, delineando el perfil de víctima y agresor; y mapeó la distribución espacial de las agresiones, mediante la emisión de medidas de protección por parte de la justicia. Se utilizaron metodologías sustentadas en el materialismo histórico y 
dialéctico, discusiones de género y desigualdades intraurbanas. Se utilizaron datos secundarios de los informes denominados "Investigación social", publicados entre 2009 y 2019, por los Juzgados $1^{\circ}$ y $2^{\circ}$ Especial de Violencia Doméstica y Familiar contra la Mujer del Distrito de São Luís. El perfil de las mujeres víctimas de violencia doméstica, en su mayor parte, son solteras y/o casadas, con edades comprendidas entre los 26 años. y 43 años, madre de uno o más hijos y sin renta fija. Los agresores tienen entre 26 y 34 años, con diferentes profesiones. Los actos violentos fueron en su mayoría cometidos por personas que ya no tienen relaciones afectivas con las víctimas y entre las motivaciones de la violencia se destacan la inconformidad con el fin de la relación, los celos, entre otros. La distribución espacial de la violencia contra las mujeres es heterogénea en la escala intraurbana de la capital de Maranhão, revelando una cierta desigualdad social, ya que la mayoría de las medidas de protección fueron otorgadas a mujeres que viven en barrios pobres y periféricos, pero esto no significa que no está en vecindarios con poblaciones de mayores ingresos. Incluso con el crecimiento del acceso a servicios especializados para denunciar y proteger a víctimas de violencia de género, se considera que aún están mal distribuidos por la ciudad.

Palabras clave: Desigualdades intraurbanas; Perfil socioeconómico; Geografías feministas.

\section{Introdução}

A violência contra a mulher no mundo e Brasil tem sido bastante denunciada desde a década de 1970, através dos movimentos sociais que alertavam sobre a violência doméstica e sexual (GOHN, 2007). Organismos e instituições internacionais e nacionais têm divulgado como as violências contra as mulheres são expressivas e banalizadas nas relações sociais, e buscam a criação de planos e estratégias para o fim das agressões. Sabe-se que esse fenômeno pode ocasionar várias consequências, dentre as quais as sequelas físicas e psicológicas, podendo chegar à letalidade feminina.

No Brasil, a Lei $n^{\circ}$. 11.340/2006, alcunhada de Lei Maria da Penha, visou dentre os seus objetivos, assegurar assistência e proteção às vítimas de violência e mudanças nos procedimentos judiciais, como a criação das Varas e/ou Juizados Especiais para atuação na área (BRASIL, 2006). Em São Luís, Maranhão, a atuação mais específica se deu através da criação, em 2008, da $1^{a}$ Vara Especial de Violência Doméstica e Familiar contra a Mulher (V.D.F.M.).

Em 2009, a $1^{\text {a }}$ V.D.F.M iniciou o levantamento dos dados sobre as mulheres em situação de violência, em forma de relatórios técnicos denominados "Pesquisa Social", publicados pela própria entidade no formato de dados brutos. Inicialmente, a divulgação dos relatórios ficou restrita aos eventos organizados pela $1^{\mathrm{a}}$ V.D.F.M., encontrados posteriormente em forma impressa nos arquivos físicos do próprio órgão; e a partir de 2017, os relatórios passam a ser disponibilizados na biblioteca da Casa da Mulher Brasileira, em São Luís.

Deste modo, o presente artigo objetivou analisar o perfil da vítima e agressor e mapear a distribuição espacial das agressões nos bairros de São Luís-MA, tendo como base os relatórios publicados pela V.D.F.M. no período de 2009 a 2019. Compreende-se que essa análise é necessária para melhor entendimento da violência de gênero e visa contribuir, através da investigação geográfica, com as instituições da segurança pública que tratam da violência contra a mulher.

Para nortear as discussões levantadas, consideramos as apreensões de Santos (2017) e De Moreira (1982) sobre o conceito de espaço, que o compreende como uma força ativa que molda as experiências sociais e, portanto, revela as tensões que atravessam as relações humanas. Nesse sentido, pautamo-nos nos estudos de Rose (1993), Silva (2003), Pastana (2005), Gohn (2007) e entre outras que destacam como as relações de gênero, enquanto relações de poder e hierarquia, interferem na compreensão do espaço, expondo um assimétrico desenvolvimento socioespacial.

Segundo Saffioti (2013), a dimensão sociocultural e dos papéis de gênero socialmente construídos reforçam um sistema de dominação pautado na organização e distribuição de poder entre os sexos, que usa ações coercitivas capazes de subjugar indivíduos e grupos, justificados em nome da tradição, da exclusão de indivíduos da vida pública, da determinação de ocupações e exercício quase exclusivo em tarefas distintas. Assim os locais aqui revelados onde ocorrem os atos violentos repercutem como o uso dos espaços será distinto segundo os papéis socioculturais de gênero, de raça e etnia, de classe social e outros elementos representativos.

\section{Materiais e métodos}

A pesquisa é descritiva e documental, tendo como suporte as percepções proporcionadas pelo materialismo histórico e dialético como forma de compreensão e explicação da sociedade, pois este é um 
"método de desenvolvimento e explicitação dos fenômenos culturais partindo da atividade prática objetiva do homem histórico" (KOSIK, 1995, p. 39). Deste modo será possível analisar as contradições da realidade, as desigualdades intraurbanas da violência de gênero e os fatores culturais, que mantêm os espaços em constante transformação (KONDER, 2008).

De acordo com Gil (2019), as pesquisas descritivas têm como objetivo a exposição das características de determinado fenômeno ou de uma população, enquanto a pesquisa documental é aquela cuja fonte é interna às instituições, que estão mantidas em arquivos de empresas, órgãos públicos e outras organizações. Destarte, para a análise documental utilizaram-se os dados secundários provenientes dos relatórios denominados "Pesquisa Social", realizados entre 2009 e 2019, pela 1ª 2 2 V.D.F.M. da comarca de São Luís.

Os dados analisados neste artigo são o resultado do quantitativo de 4.967 processos consultados ao longo de 10 anos de publicações. Vale ressaltar que tais dados tiveram como fonte os processos de solicitação de medidas protetivas de urgência, requeridas nas próprias Varas ou por outras entidades de direito, ou seja, aquelas resultantes dos boletins de ocorrência e petições, todavia nem todo boletim de ocorrência resulta ou requer medidas protetivas para a vítima.

Devido à alta demanda dos processos, bem como o reduzido número de colaboradores nas respectivas Varas de Justiça, todas as demais informações, tabulações e mecanismos de compilação de dados não foram transcritos. Desse modo, a análise do material, que poderia ser muito mais abrangente, limitou-se aos 30\% de cada ano, quantitativo que os próprios relatórios compilaram. A "Pesquisa Social", inicialmente, teve como fonte os processos de medidas protetivas de urgência, cujos dados primários procederam de Boletins de Ocorrência da Delegacia da Mulher e outras delegacias, denúncias originadas da Defensoria Pública, do Ministério Público e entre outros, onde cada órgão e instituição define sua metodologia de aferição de informações e confluência de dados, ou seja, devido a diversidade quanto à forma de apreensão das denúncias, há lacunas de informação de categorias e temas de análise.

Assim, devido à incompletude dos dados registrados no ato das denúncias, as "Pesquisas Sociais" apresentam lacunas. Os dados primários autodeclarados pelas mulheres vítimas não permitem algumas análises mais acuradas sobre o agressor como, por exemplo, a cor da pele, escolaridade, renda, dentre outros. Portanto, para melhor compreensão do cenário da violência de gênero, foram realizadas entrevistas informais com os servidores que estiveram à frente do levantamento de dados dos relatórios da $1^{\mathrm{a}}$ e $2^{\mathrm{a}}$ V.D.F.M., especificamente uma juíza, uma assistente social e uma comissária da infância e juventude.

A tabulação dos dados seguiu três categorias, com as respectivas unidades, utilizadas nos relatórios: o perfil da vítima (idade, estado civil, educação, profissão, renda, existência de filhos e a paternidade dos mesmos, tempo de convívio com o agressor, dentre outros); o autor da violência (além das informações contidas no formulário da vítima, busca-se identificar se o agressor estava sob efeito de bebidas alcóolicas e/ou de drogas, e a relação do agressor com a vítima); quanto ao ato violento (local de ocorrência, tipo de violência, uso ou não de armas no ato violento, e o tempo de exposição da vítima à violência).

Destaca-se que na "Pesquisa Social" houveram duas formas de padronizar os intervalos das faixas etárias dos pesquisados. No período de 2009 a 2010, os intervalos foram divididos em nove grupos e a partir de 2011 foram reduzidos em seis, com a criação de um novo grupo para visibilizar mulheres vítimas com idade acima de 60 anos. Essa mudança está relacionada à prevalência da violência no decorrer da vida das mulheres (DATAFOLHA; FBPS, 2019) e, conforme ressaltam Rose (1993) e Silva (2003), enfatiza o peso da cultura nos papéis de gênero que inferioriza as mulheres e as submete à dominação masculina, naturalizando situações violentas nas distintas faixas etárias.

Para Silva (2003), considerar o conceito de gênero implica mostrar a preocupação pela maneira que a diferença e o poder operam nas relações com e através dos processos socioespaciais, de modo que, ao serem utilizados e aplicados vários métodos, desde a investigação espacial analítica computadorizada até análises de cunho qualitativo e quantitativo, o que irá alicerçar o uso dessas metodologias será a contínua reflexão acerca das múltiplas formas em que o poder influi em toda a sociedade.

\section{Resultados e discussões}

\subsection{Reflexões sobre a pesquisa social (2009-2019)}

Em São Luís a criação da $1^{\text {a }}$ V.D.F.M., em 2008, representou a atuação mais específica do judiciário em processar, julgar e executar causas decorrentes da prática de violência doméstica e familiar contra a mulher. No ano seguinte iniciou o levantamento e publicou em forma de pareceres técnicos denominados "Pesquisa Social", as informações sobre as mulheres em situação de violência; tendo como fonte os processos de medidas protetivas de urgência requeridas na própria Vara ou por outras entidades de direito. Em setembro de 2017 foi 
criada a $2^{\text {a }}$ V.D.F.M., como forma de dar celeridade aos processos de medidas protetivas que tramitavam em São Luís e oferecer suporte jurídico às vítimas.

Em novembro de 2017 foi inaugurada a Casa da Mulher Brasileira, um órgão de responsabilidade da Secretaria da Mulher do Estado do Maranhão e com estrutura física que comporta serviços especializados em atendimento para os mais diversos tipos de violência contra as mulheres, que compõem a "Rede de Atendimento Especializado à Mulher", contando com o apoio psicossocial, de delegacia especializada, Juizado, Ministério Público, Defensoria Pública e entre outros. Neste mesmo ano a $2^{\text {a }}$ V.D.F.M. passa a funcionar na Casa da Mulher Brasileira, tornando-se responsável pelo prosseguimento do desenvolvimento e publicação da "Pesquisa Social", passando a disponibilizar o acesso às suas informações na biblioteca do prédio ou divulgando através dos eventos em alusão a violência de gênero realizados em São Luís.

Em 2009, a 1 ${ }^{a}$ V.D.F.M. publicou a "Pesquisa Social" que teve como fonte os 312 processos registrados entre agosto e novembro de 2008 (entre ações penais, medidas protetivas e inquéritos policiais). Assim, entre 2009 e 2019, foram publicados os relatórios anuais sempre com base no ano anterior, com exceção do único relatório que compreendeu 2012 e 2013, conforme a Tabela 1. Ratificando que esses números representam apenas trinta por cento, de cada ano, dos processos registrados, avalia-se que o número real é bem maior.

Tabela 1: Número de processos registrados em cada ano

\begin{tabular}{cc}
\hline ANO & $\mathbf{N}^{\mathbf{0}}$ DE PROCESSOS \\
\hline 2009 & 312 \\
2010 & 533 \\
2011 & 513 \\
$2012-2013$ & 435 \\
2014 & 414 \\
2015 & 508 \\
2016 & 505 \\
2017 & 542 \\
2018 & 1.205 \\
\hline Fonte: Adaptado da Pesquisa Social 2009-2019.
\end{tabular}

Considerando que o relatório de 2009 contabilizou apenas quatro meses do ano anterior, tem-se como pressuposto que o pequeno o número de processos analisados em comparação aos demais anos relaciona-se em função do início da atuação do órgão em São Luís. Na sequência, observa-se a média de mais de 500 casos anuais, cujas variações podem ser compreendidas por diversas razões, tais quais a popularização da atuação do órgão ante à sociedade civil, os trabalhos integralizados de serviços entre os órgãos que fazem parte da "Rede", o papel dos meios de comunicação quanto à conscientização sobre a violência doméstica, as campanhas estaduais e municipais de enfrentamento à violência de gênero e entre outros, culminando com um incremento no número de processos analisados nos últimos anos, principalmente o de 2018, que praticamente duplicou o registro, com 1.205 casos estudados e contemplados na pesquisa.

\subsection{O Perfil da vítima que procura atendimento nas $1^{a}$ e $2^{a}$ V.D.F.M.}

No relatório de 2009, que correspondeu aos meses de agosto a novembro de 2008, as mulheres entre 31 e 35 anos foram as que mais denunciaram a violência, buscaram atendimento e foram incluídas nas medidas protetivas de urgências. No relatório seguinte, em 2010, prevaleceu a faixa etária de 26 a 30, como pode-se compreender na Figura 1. No período de 2011 a 2018, a faixa de maior denúncia foi das mulheres entre 26 e 34 anos, como visto na Figura 2.

É possível constatar, conforme os dados expostos nas Figuras $\mathbf{1}$ e 2, que o número de mulheres com faixa etária acima dos 60 anos foi pequeno. Uma das possíveis explicações, descrita no relatório de 2011, é que nos anos anteriores haviam vítimas idosas, mas a quantificação era pequena para ser tabulada. Portanto, esses dados foram subnotificados, mas revelam que a violência de gênero se estendia também às mulheres idosas nos anos de 2009 e 2010. No período subsequente, os registros foram considerados. 


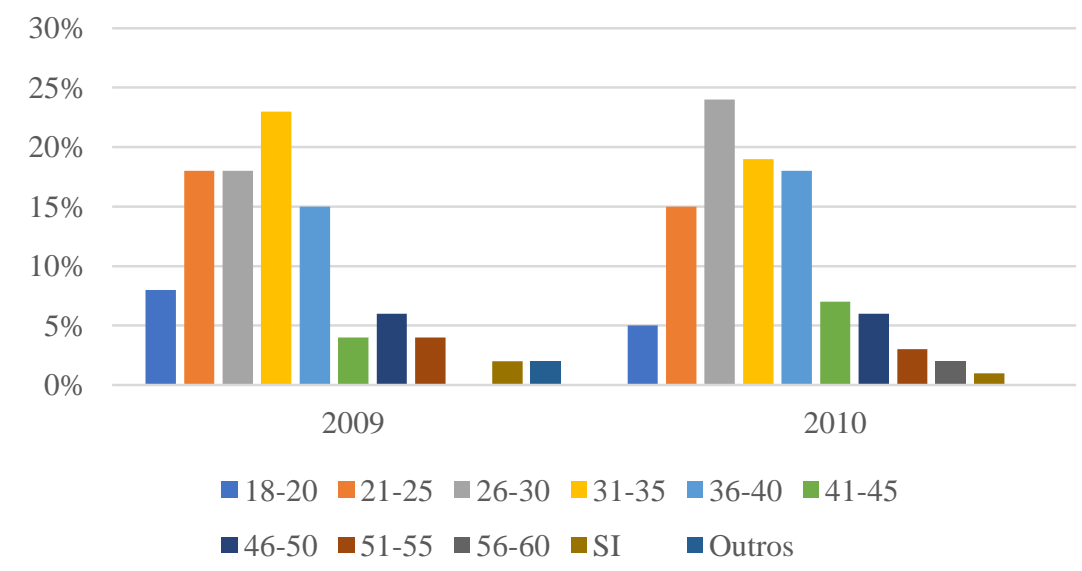

Figura 1: Faixa etária das vítimas em 2009 e 2010. Fonte: Elaborado pelas autoras.

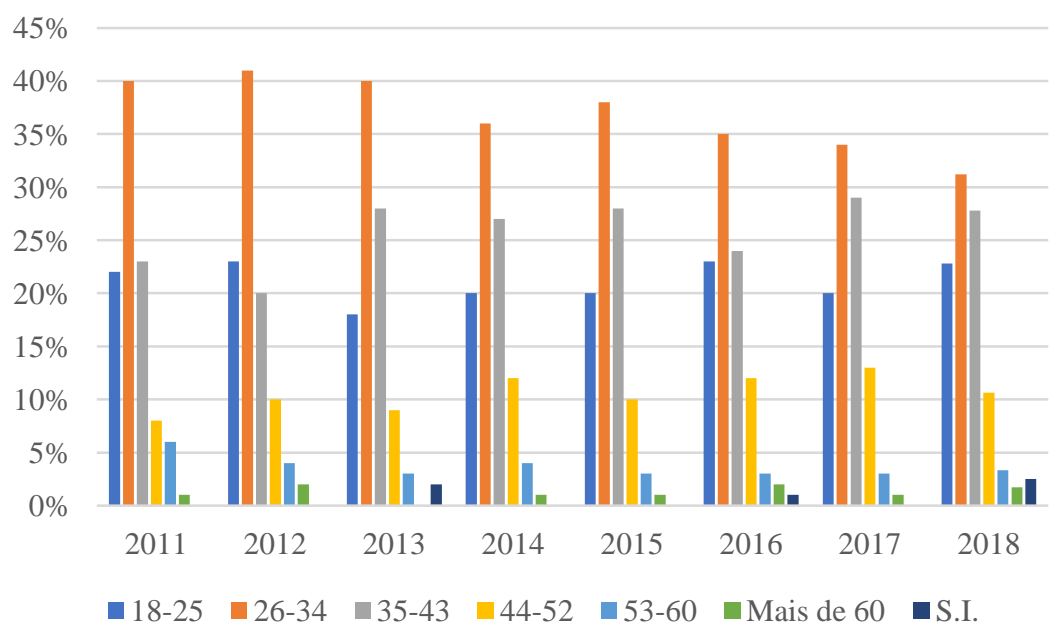

Figura 2: Faixa etária das vítimas de 2011 a 2018. Fonte: Elaborado pelas autoras.

Em geral, a subnotificação dos registros pode estar relacionada à falta de apoio de amigos e/ou familiares ou a descrença destes em relação à situação relatada, desmotivando aquela que se encontra em um relacionamento abusivo a cortar as relações afetivas violentas e buscar apoio jurídico; à falta de tempo livre da vítima para formalizar a denúncia; o apaziguamento da violência obtido a partir da ajuda e influência da família e amigos; a crença na mudança de hábitos de seu agressor e entre outros (DATASENADO, 2015).

Em análise sobre o perfil das mulheres vítimas de violências, Labronici et al. (2010) verificam que a maioria dos atos violentos têm percentagens mais elevadas nos grupos de mulheres jovens que denunciaram atos relativos ao assédio sexual, moral e patrimonial, todavia as autoras afirmam que a categoria idade tem total correspondência à matriz de origem e à cultura relacionada aos papéis de gênero, pois as mulheres mais velhas não percebem situações violentas ou não optam pela denúncia em razão da sua criação e educação, do peso cultural, religioso, econômico e entre outros.

Quanto ao estado civil, a prevalência de mulheres "solteiras" se mantém em todos os relatórios, demonstrando que a violência de gênero transcende relacionamentos estáveis de longo prazo e se assenta na proximidade do opressor com a vítima que, em geral, deixou de ter convívio íntimo com a mesma (DATAFOLHA; FBSP, 2019). Tal dado confirma ainda a não aceitação do agressor com o fim do relacionamento e que, por conhecer o local de moradia, a vida social e/ou profissional da vítima, passa a perseguir e coagir a ex-companheira, levando às violências.

Em dez anos da "Pesquisa Social", 2009-2019, as mulheres que se declararam "solteiras" foram as que mais procuraram os serviços de proteção à vítima de violência, seguidas de mulheres com "relação conjugal" e em "união estável". É válido salientar que o principal alvo dos atos violentos, as mulheres solteiras, pode ser um indicador de vulnerabilidade percebido pelos agressores, que passam a realizar atos de perseguição, humilhação e diferentes formas de assédio (COLOMBARA; PELIZZARI, 1999), mas também um fator predisponente para a denúncia da violência, visto ser inexistente o vínculo matrimonial. 
Moura, Netto e Souza (2012) ao discutirem o perfil da vítima, atentam para a quantidade de denúncias realizadas e asseveram que a maioria das mulheres que se declaram solteiras têm um companheiro afetivo, mesmo que não estejam em uma relação estável e, quando se tornam alvo de violências, sentem-se inseguras, frágeis e têm medo de pôr fim ao início do que se tornaria um relacionamento ou mesmo de serem punidas pelo companheiro. Segundo as autoras, no caso de mulheres casadas ou em união estável, cujo tempo de convivência com o companheiro é maior, tem-se um perfil de dependência social, emocional e/ou financeira, situação que favorece ao homem uma ideia de "proprietário" da parceira, considerando estar no direito de praticar qualquer violência.

Relacionamentos de longa duração guardam fatores que contribuem para a violência, como o isolamento (que pode ser social, geográfico, físico ou afetivo), a fragmentação (que considera outrem o responsável por um problema vivido), o poder e o domínio, ou a influência moral (CARVALHO, 2010). Desta forma, nota-se nas denúncias e dados, a existência de um perfil de violência conjugal e em relações estáveis, que repercute no papel da mulher a figura mais frágil da relação; mas ainda assim, aponta para a quebra do paradigma de violência na reação da vítima em buscar fim à situação que se encontra, independentemente de seu estado civil.

Quanto à escolaridade, a "Pesquisa Social" demonstra carência de dados para melhor compreensão dessa informação. Entretanto, nos cinco primeiros anos, mulheres denunciantes autodeclararam possuir ensino médio completo ou inferior a esse. Nos anos de 2014, 2016, 2017 e 2018 autodeclararam ter ensino superior completo. Cabe refletir se o nível de escolaridade das mulheres foi capaz de influenciá-las a optar pela denúncia dos abusos sofridos e se, por esse motivo, o número de denúncias aumentou nos últimos anos da pesquisa. A inexistência de informações sobre a escolaridade compromete a real compreensão da influência da educação no combate à violência de gênero, todavia fica claro que políticas voltadas para a educação da população, como campanhas de prevenção e denúncia, são aliadas no combate da violência contra a mulher (DATAFOLHA; FBSP, 2019).

Pode-se inferir com estes dados que as mulheres com menor de nível de escolaridade são as que mais receiam em denunciar a violência e as que mais vivenciaram-na. Em uma pesquisa pelo DataSenado em parceria com o Observatório da Mulher contra Violência (2020), realizada em todo o país, constatou-se que, de um total de 2.400 mulheres entrevistadas, $68 \%$ declararam conhecer pouco sobre a Lei e $11 \%$ afirmaram não conhecer nada, estando claro a dificuldade das mulheres em reivindicarem seus direitos sem conhecê-los. A pesquisa afirma que 7 em cada 10 mulheres não acredita que a Lei Maria da Penha (Lei $\mathrm{n}^{\mathbf{0}}$ 11.340/06) as protejam contra a violência doméstica e familiar, ressaltando um sentimento de frustração das vítimas em relação às delegacias, juizados e varas.

Segundo o Fórum Brasileiro de Segurança Pública, a educação é responsável por prevenir casos de violência, pois está diretamente relacionada ao acesso à informação, que pode levar a vítima, parentes e amigos a reconhecerem outras lesões de violência além daquelas visíveis por machucados, feridas ou lesões, como as formas de violência psicológica, moral, patrimonial ou mesmo a importunação sexual, ou assédio. Uma escolaridade precária pode contribuir para que as vítimas sejam dependentes e tolerantes a seu agressor (DATAFOLHA; FBSP, 2019).

Quanto à ocupação e renda das mulheres houve incompletude das respostas. Contudo, pode-se asseverar que em uma década de monitoramento, nos relatórios que constavam esses dados, foi possível perceber que a maioria das mulheres se autodeclararam com "donas de casa"; portanto sem renda, ratificando a hipossuficiência que tais mulheres se encontram e, consequentemente, uma dependência socioeconômica de terceiros, como familiares de laços consanguíneos ou parceiros afetivos. Em muitos casos, esse grupo está inserido naqueles de estado civil de relacionamentos longos, o que remete à dificuldade que as mulheres têm de romper com o ciclo de violência de gênero o qual está exposta.

Nas demais ocupações autodeclaradas, apareceram ranqueadas em segundo ou terceiro lugar "estudantes" ou "empregadas domésticas". Em 2009 e 2019, as "estudantes" representaram o segundo lugar, ratificando a inópia fonte de renda e consequente carência em condições de sustentar a si própria ou a outrem. E, no período de 2010 a 2018 as "empregadas domésticas" permaneceram em segundo lugar, que aponta para o espaço de trabalho tradicionalmente mais disponível às mulheres, muitas vezes trabalhando na informalidade, sem registros na carteira de trabalho e/ou garantias sociais e de renda. Em ambas as profissões, a dependência financeira pode ser um fator explicativo para a permanência das mulheres nos relacionamentos violentos.

Moura, Netto e Souza (2012) afirmam que, para mulheres com menos recursos, o fator financeiro é um impeditivo para a realização da denúncia, entretanto tal questão não existe para mulheres com melhores condições de renda. No lugar do medo, a vergonha em assumir ser vítima de violência e ser criticada toma a 
posição principal entre os motivos quanto à subnotificação de tais casos, relacionados ainda à dependência emocional, receio de perder o padrão de vida e, nos casos que envolve os filhos, perder a guarda ou a condição de vida adequada ao seu crescimento. Por tais razões, será comum observar em tais perfis traçados a partir de dados públicos uma participação majoritária de mulheres em atividades ligadas ao emprego doméstico.

Quanto à maternidade os relatórios asseveram que a maioria das mulheres declarou possuir 1 ou 2 filhos e a paternidade era do relacionamento atual, com mais da metade dos casos, excetuando-se o ano de 2013, cuja paternidade dos filhos estava associada a relacionamentos anteriores. Esses dados demonstram que mulheres mães tentam, ao longo da vida da criança, apaziguar a relação com o agressor, porém em um dado momento não aguentam mais a situação de violência e buscam intervenção do Estado, por outro lado, confirmam indicadores que atestam que as mulheres mães não formalizam denúncias por medo de retaliações, por não conseguir impedir que os maus tratos se estendam a seus filhos, e por depender do agressor para a criação dos filhos (LISBOA et al., 2003).

Outro aspecto a ser mencionado é que a "Pesquisa Social" não compreende, na divulgação dos relatórios, o quesito raça/cor da pele. Entretanto, através de entrevistas com os servidores que elaboraram os relatórios, estes afirmaram que a maioria das mulheres que buscaram assistência estatal e medidas protetivas eram negras. Essa informação foi baseada no ato do registro das denúncias nos boletins de ocorrência ou petições que anexam a foto da identidade das vítimas aos processos, dado não computado em razão de não ter ocorrido a autodeclaração da cor ou raça pela vítima, conforme orienta o IBGE.

O sexismo e o racismo presentes na realidade brasileira reverberam a condição sociocultural feminina, no entanto, de acordo com o Ipea (2017), a posição que mulheres negras e pobres estão inseridas é aquela de postos de trabalho mais subalternizados e mal pagos quando há o vínculo empregatício, visto terem a maior participação em níveis de desemprego segundo sexo e cor da pele. Tais indicadores, relacionados à maternidade, comprovam o crescimento de famílias chefiadas por mulheres com filhos e a nítida ocupação majoritária de mulheres negras em trabalhos domésticos.

\subsection{O Perfil do autor da violência denunciados nas $1^{a}$ e $2^{a}$ V.D.F.M.}

Dentre os autores da violência, a faixa etária com maior registro autodeclarado pelas mulheres denunciantes foi do grupo com 26 a 34 anos de idade, identificado nos relatórios no período de 2009 a 2019, com exceção do ano de 2010, em que foi mais recorrente de 36 a 40 anos. Carvalho (2010) busca compreender a relação da idade com a agressão perpetrada pelo autor da violência a partir do descontrole emocional, hostilidade e frustração do agressor face à sua própria condição e personalidade antissocial e um frágil autocontrole externo, afirmando que tais características são mais nítidas na faixa etária majoritária.

Quanto ao estado civil, os "solteiros" aparecem com a maior representação em todos os anos, seguidos daqueles "casados"; e, em terceiro, os de "união estável". Houve exceção em 2010 e 2018, quando aqueles em "união estável" aparecem à frente dos "casados". Entretanto, estar solteiro não é uma condição para a nulidade de atos violentos, pois geralmente atores violentos o são em novos e antigos relacionamentos, com ações hostis, ciumentas e de reafirmação de posse (CALDEIRA, 2012). No que se refere ao nível de escolaridade, não é possível identificar um perfil, pois a maioria dos dados coletados não oferecia informação. Dos processos possíveis de apreensão, entre 2009 a 2019, a maioria dos denunciados pode ser agrupada entre naqueles que têm "ensino médio completo" ou "inferior", não sendo possível determinar um demonstrativo da realidade.

Quanto às relações de trabalho e de renda, na maioria dos processos, os valores não foram declarados, seguidos por aqueles que possuem renda de até 2 salários mínimos, excetuando-se a pesquisa referente ao ano de 2017 em que a maioria declarou que o agressor recebe acima de 2 salários mínimos. Dentre as profissões identificadas, as mais recorrentes foram os "motoristas", seguidos pelos "pedreiros", "auxiliar de pedreiro" e "autônomos". No ano de 2009, o trabalho de "vigilante" tem incidência além daqueles já citados; nos estudos de 2010 a 2013 aparecem situações em que o agressor é declarado como "desempregado"; entre 2015 e 2016, aparece a profissão de "mecânico"; e em 2017, a profissão "estudante", dado que não constava nos anos anteriores.

O uso de álcool e entorpecentes são elementos citados pelas mulheres atendidas como influenciadores e estimuladores da violência perpetrada contra estas. Nas Figura 3 e Figura 4, é possível identificar que em muitos casos as drogas e/ou de bebidas alcoólicas foram consumidas pelos agressores, no momento do ato violento. Tais indicadores chamam a atenção pela influência de tais substâncias no cenário de violência, podendo potencializar o ato em si. 


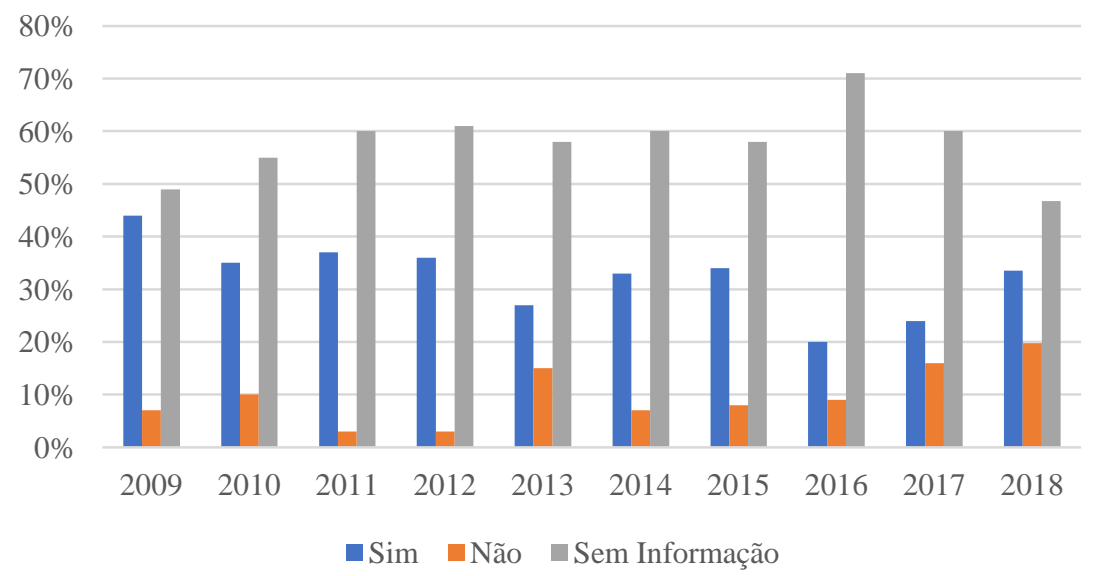

Figura 3: Uso de álcool pelo agressor no momento do ato violento, de 2009 a 2018. Fonte: Elaborado pelas autoras.

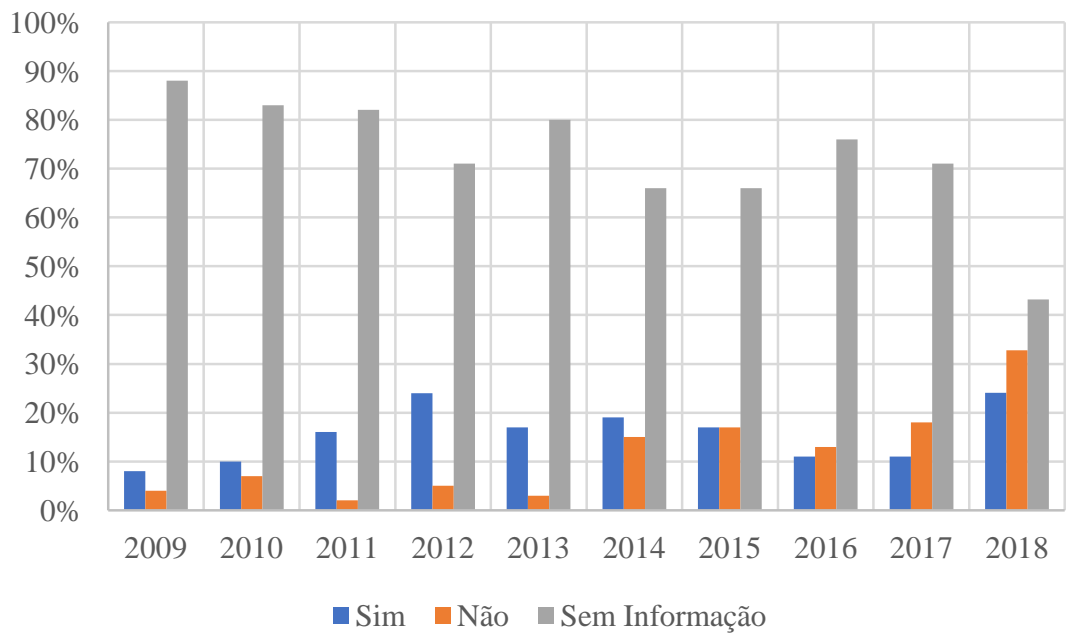

Figura 4: Uso de drogas pelo agressor no momento do ato violento, de 2009 a 2018. Fonte: Elaborado pelas autoras.

O acesso e o uso nocivo de álcool e drogas interferem e se associam à violência de gênero, pois implicam na geração de comportamentos agressivos por parte do autor da violência. Ressalta-se ainda que os dados que apontam a não utilização de álcool ou drogas no momento do ato violento não exime a influência de tais substâncias quanto à situação de violência, visto que críticas ao hábito de consumo feitas pelas vítimas aos seus companheiros também são causas de discussões que podem levar a episódios de violência (D'OLIVEIRA et al., 2009).

Com relação ao tempo de convivência da vítima com o agressor, a maioria dos casos referem-se aos relacionamentos que duraram de 01 a 05 anos, nas relações afetivas com "namorado", "companheiro" ou "cônjuge". Ressalta-se que nos casos em que o agressor se trata do "pai", "padrasto", "tio", "irmão", "filho", "cunhado" ou "amigo" da vítima, não apareceu tempo de convívio, porém confirma-se a relação íntima a qual o agressor se apropria para executar o ato de violência, que transcende o corpo físico e perpassa a saúde emocional e psicológica.

No que diz respeito ao tipo de relação entre a vítima e o agressor, em todos os anos de levantamento de dados, ou seja, de 2009 a 2019, a maioria dos casos expõe o "ex-companheiro", seguidos de "ex-esposo" e "ex-namorado" como os principais responsáveis, dado que pode ser diretamente relacionado às causas apontadas para a prática do ato violento, como o inconformismo com o fim do relacionamento e o ciúmes, sentimentos de posse do agressor em relação à vítima e a subjugação desta às vontades que lhes apraz (DATASENADO, 2015).

É nítido o peso da proximidade afetiva nos casos de violência de gênero, pois a maioria dos agressores são apontados como antigos parceiros que faziam parte das atividades cotidianas da vítima, revelando que, dentre as mulheres vítimas de violência doméstica, a maioria teve como opressor a pessoa sem laços 
consanguíneos e escolhida por elas para conviver intimamente, e que ao optar por romper o relacionamento, abusivo ou não, ou com a situação de violência, continuaram a ser assediadas, chantageadas e violentadas.

Vale registrar como um ponto de dificuldade para o rompimento do relacionamento violento, a tolerância ou impossibilidade da mulher de sair da situação de violência com o cônjuge, companheiro ou namorado, situação composta por vários fatores como sentimento de vergonha; falta de informações sobre seus direitos; ameaças; dependência econômica; zelo pela unidade da família e crença na mudança do agressor; não credibilidade nas instituições de segurança e judiciais entre outros (DATASENADO, 2015).

Tais dificuldades ou tolerâncias, quando analisadas ao tempo de convívio entre vítima e agressor, confirmam as análises de Carvalho (2010) quando afirma que a mulher vítima de violência encontra-se em um grupo de alto risco de vida, de incapacidades e sequelas que incidirão de forma crônica em sua saúde física e emocional e sua conjuntura pessoal, social e familiar. Para a autora, não apenas no período em que sofre a violência, mas em todos os anos vindouros, a mulher vítima terá consequências nefastas na sua qualidade de vida e que poderão constar de desordens médicas, psicológicas e de conduta.

\subsection{Quanto ao ato violento}

Nessa categoria análise, busca-se apreender as modalidades do ato violento segundo a tipificação e conceito de violência contidos na Lei $\mathrm{n}^{\circ}$. 11.340/2006, Lei Maria da Penha (BRASIL, 2006). Nesse sentido, as "Pesquisas Sociais" dos anos 2009 e 2010 apontam para o ato violento mais recorrente a violência física, seguido pela ameaça e a ofensa moral ou injúria, em ambos os anos. Porque a violência, em geral, não ocorre avulsa a outras tipificações, nota-se a ocorrência de duas ou mais classificações de ato violento.

De 2011 a 2019, a coleta de dados pôde registrar como ato violento majoritário a prática de violência psicológica, ou seja, aquela pautada na degradação e controle de ações, comportamentos, crenças e decisões da vítima por meio da intimidação, manipulação, ameaças direta ou indireta, entre outras. Em conseguinte, a violência moral e injúria, assim como a violência física apontam nos dados como os tipos mais frequentes. Em todas as pesquisas, a violência patrimonial aparece como a quarta mais recorrente.

Em todo o período analisado, a violência sexual apareceu como a de menor registro, provavelmente destacando uma subnotificação e o desconhecimento das vítimas em notar o ato violento nas relações de pequena ou longa duração que, em geral, é praticado quando o parceiro a obriga a manter o contato sexual por meio da força, intimidação, coerção, chantagem, manipulação e outros mecanismos que anulem ou limite a vontade da mulher, o que caracteriza o estupro conjugal.

O principal local de agressão registrado nas denúncias é a do ambiente familiar da "casa", ambiente privado, fora do olhar e do conhecimento de familiares, amigos, vizinhos ou outros, como visto na Tabela 2. Ressalta-se ainda a ocorrência de mais de um local na prática do ato violento, explicado por situações em que a vítima, deixa o ambiente doméstico para buscar ajuda e o agressor inicia sua perseguição; ou quando em situações e lugares diferentes, o agressor ao confrontar a vítima, inicia a prática da violência.

Tabela 2: Local onde ocorreu os atos violentos, de 2009 a 2018.

\begin{tabular}{lrrcc}
\hline Ano & Em casa & Na rua & Casa de familiares & Outros \\
\hline 2009 & $77 \%$ & $17 \%$ & $3 \%$ & $3 \%$ \\
2010 & $54 \%$ & $19 \%$ & $17 \%$ & $8 \%$ \\
2011 & $67 \%$ & $17 \%$ & $4 \%$ & $12 \%$ \\
2012 & $69 \%$ & $16 \%$ & $1 \%$ & $14 \%$ \\
2013 & $63 \%$ & $21 \%$ & $4 \%$ & $12 \%$ \\
2014 & $71 \%$ & $19 \%$ & $2 \%$ & $8 \%$ \\
2015 & $66 \%$ & $20 \%$ & $5 \%$ & $9 \%$ \\
2016 & $72 \%$ & $12 \%$ & $2 \%$ & $14 \%$ \\
2017 & $69 \%$ & $10 \%$ & $3 \%$ & $18 \%$ \\
2018 & $67 \%$ & $12 \%$ & $3 \%$ & $18 \%$ \\
\hline
\end{tabular}

Fonte: Elaborado pelas autoras.

Nota-se que o segundo local de maior ocorrência da agressão são os espaços públicos, em especial a "rua", lugares de comum trânsito de pessoas e por isso, presumivelmente vistos pela vítima como busca de socorro ou proteção de outrem que esteja no caminho. De 2009 a 2015, o $3^{\circ}$ lugar de maior incidência da violência de gênero é apontado na pesquisa por "outros", identificado como os espaços de trabalho, lazer ou mesmo em meios eletrônicos como redes sociais, demonstrando a clara perseguição do agressor à mulher. 
Segundo Colombara e Pelizzari (1999), apenas no espaço da casa, há diversos fatores que podem incrementar o risco potencial de ocorrer a violência doméstica ou intrafamiliar, entre eles, estão o tempo em que os familiares estão juntos e suas interações sociais; o número de tópicos e atividades de interesse em comum; a intensidade dos laços interpessoais; as diferenças de opiniões que afetam o cotidiano familiar e seus membros; a capacidade de influência de comportamentos, valores e atitudes de outros membros da família; as diferenças de idade e sexo e os papéis atribuídos a cada um; o estresse atribuído ao ciclo de vida, a mudanças econômicas e entre outros.

Relacionamentos de longa duração, por exemplo, contém condições que contribuem para a violência, como o isolamento (que pode ser social, geográfico, físico ou afetivo), a fragmentação (que considera outrem o responsável por um problema vivido), o poder e o domínio, ou a influência moral (CARVALHO, 2010). Mulheres que se unem a um parceiro de modo involuntário, ou seja, quando há pressão familiar pela duração do relacionamento ou por motivos de gravidez; vivem com companheiros ciumentos de grau patológico; e o grau de conhecimento íntimo da vida de cada um, seus pontos fracos, medos e preferências podem ser usados como motivadores de violências.

Estes e outros fatores intensificam a vulnerabilidade da família e da mulher, transformando qualquer conflito um fator de risco para a violência. Atrela-se ainda a natureza privada do ambiente doméstico, e como as relações de gênero estão estruturadas no contexto familiar, de forma vertical cuja hierarquia segue critérios de idade e sexo, e como o grau de rigidez de tais hierarquias, de crença em torno da importância da obediência e do respeito, da disciplina, ou mesmo o grau de adesão dos membros familiares a estereótipos de gênero e a autonomia que cada um deve ter, consiste-se em condicionantes sobre o potencial de violência que uma família pode estar exposta (COLOMBARA; PELIZZARI, 1999).

Pastana (2005) assinala que o medo influencia as relações socioespaciais a tal ponto que mesmo a escolha de que bairro morar ou o tipo de residência escolhida serão permeados pela busca por segurança. Deste modo, é cada vez mais constante os cuidados pessoais com horários, trajetos a serem permeados, os meios de locomoção e os locais frequentados, pois tanto simbólica quanto materialmente, as estratégias de proteção e reação multiplicam regras de exclusão e restringem movimentos, sendo mais persistentes segundo as condições sociais pertencentes ao gênero, visto que as mulheres estarão mais propensas aos diversos tipos de violências nos espaços públicos, confirmando os dados que indicam tais espaços como aqueles que mais ocorreram atos violentos, depois do ambiente doméstico.

Mesmo quando a rua, enquanto espaço de comum trânsito de pessoas, é vista por vítimas de violências nos ambientes domésticos, como busca de socorro ou proteção de outrem que esteja no caminho, as múltiplas violências as quais mulheres estarão suscetíveis nesses espaços transporão as demais situações. Além disso, locais institucionais, geralmente buscados por vítimas de violências, também reproduzirão e acometerão mulheres a novas violências, como é o caso dos sistemas e serviços especializados de atendimento à mulher, que desacreditam a vítima e dispensam tratamentos hostis que a afugentam, fazendo-a descredibilizar os órgãos (DATASENADO, 2020).

Em pesquisa sobre a violência de gênero no ambiente digital ocorridas no Brasil, realizada pela Coding Rights e Internetlab para a ONU (2017), o assédio moral configura como o principal tipo de violência praticado nas redes sociais, seguido pela exposição de conteúdos íntimos, impróprios e violentos. Os organizadores relatam que a expansão do local da violência para a internet configura na prática em que o agressor, utilizando-se do anonimato e/ou da difusão em larga escala de suas publicações virtuais, usa de plataformas online para perseguir, censurar, e manifestar ataques diversos à vítima.

Ao mapear os tipos de violência praticados nas redes sociais, os relatores agruparam 12 tipologias de violência de gênero (Id., 2017), confirmando a extensão da violência nos meios digitais. Com a difusão de novas tecnologias da área de comunicação (SANTOS, 2017) e o acesso cada vez mais fácil e acessível nas plataformas digitais, pode-se compreender por que os anos de 2016 a 2018 destacam-se quanto ao local da violência caracterizado como "outros" transpõe os números do espaço público da rua.

Quanto à utilização de armas, na maioria dos casos analisados entre os anos de 2009 a 2018, não houve emprego de quaisquer tipos, reafirmando o uso da força física do agressor nas situações de violência física, patrimonial e/ou sexual. Dos relatos que afirmam que o autor do ato violento utilizou algum tipo de arma, verifica-se o uso de arma branca na grande parte dos casos, seguidos de "outros", representados por toda a sorte de objetos perfuro cortantes e, por último, a utilização de arma de fogo de uso restrito.

A partir de 2010 é adicionada à pesquisa a apreensão de dados que expunham o tempo de exposição da vítima à situação de violência, com vistas a identificar os atos de violência e as marcas, físicas ou não, deixadas naquelas que buscam ajuda legal. Desta forma, até 2011 a maioria dos casos de violência ocorreram pela $1^{\text {a }}$ vez no relacionamento da vítima com o agressor e, no segundo lugar, é mais comum que ocorra a 
violência no período do primeiro ano de relacionamento. De 2012 a 2016, acentua-se relacionamentos abusivos de 5 anos ou mais, indicando a dificuldade das vítimas em romper com o ciclo da violência.

As pesquisas referentes aos anos de 2016 a 2018 mostram uma equidade em porcentagens quanto ao tempo de exposição à violência, apontando um antagonismo, pois o período do primeiro ano de relacionamento e aquele acima de 5 anos de união são os que mais se destacam no percentual dos processos pesquisados. No tópico referente à motivação para a prática do ato violento, no entanto, todos os relatórios desde 2010 ressaltam três principais motivações, a saber, o inconformismo do agressor com o fim do relacionamento, sentimentos de ciúmes e posse, e "outros".

As discussões geradas pelo uso de álcool e outras drogas, bem como discussões por disputa de bens posicionam-se $\log o$ atrás das três primeiras motivações. A partir de 2014 consideram-se questões relacionadas aos filhos ou à família como motivos apontados causadores do ato violento. De todo modo, ressalta-se que a grande maioria das causas motivadoras remete ao pensamento patriarcal que revela a relação de poder e dominação que o homem deseja exercer sobre a mulher.

\subsection{Espacialização da violência segundo os pedidos de medidas protetivas}

Sabendo que o espaço reúne a materialidade e a vida que a anima (SANTOS, 2017), a sua apreensão possibilita, a um só tempo, trabalhar as relações sociais em interação com arranjos de objetos geográficos, como processo e como resultado, abarcando sua multiplicidade e diversidade de situações e processos, resultando o espaço produzido. Conceber que o espaço é dialético e não mais um palco para as ações humanas, mas sim uma força ativa que molda as experiências sociais, significa refletir que este é um produto social ao passo que participa nos processos de produção da sociedade, revelando as tensões que atravessam as relações humanas, a distribuição de papéis, a acentuação de exclusões e hierarquizações e entre outros (DE MOREIRA, 1982).

Destarte, compreender a espacialização da violência revela, ao mesmo tempo, a banalização de um problema social que ocorre a partir da desigualdade de gênero socialmente construída ao longo dos séculos (SAFFIOTI, 2013) e, por isso, os espaços serão concebidos por mulheres e homens de formas diferentes, desde o acesso físico a determinados locais, até os muros invisíveis criados a partir de barreiras simbólicas (como o olhar) que impõem o ordenamento de uso de espaços e legitimam sua apreensão desigual a partir das relações sociais, declarando então que a história dos espaços também envolve a força, tanto física quanto simbólica (SILVA, 2003).

A espacialização da violência contra as mulheres, em São Luís-MA, reflete em parte, as suas desigualdades intraurbanas. Conforme a Figura 5, dentre os principais bairros declarados pelas vítimas, como local de residência, estão "Anjo da Guarda", "Coroadinho" e "Turu", nos três foram registrados o quantitativo entre cento e vinte e cento e noventa e seis, medidas protetivas. Na sequência, entre setenta e cinco e cento e dezenove, os bairros "Cidade Operária" e "Vila Embratel". No intervalo entre quarenta e setenta e quatro, os bairros "São Francisco", "São Raimundo", "Liberdade", "Cidade Olímpica" e "Bairro de Fátima". Os demais bairros citados ficaram nos dois últimos intervalos que abrangem entre um a trinta e nove casos de medidas protetivas emitidas.

Analisando a quantidade de pedidos de medidas protetivas em caráter de urgência, realizados por mulheres vítimas de violência de acordo com o local de habitação das requerentes, nota-se a distribuição na capital ludovicense das ações violentas, o que nos fornece a compreensão de que os atos violentos estão disseminados pela cidade (Figura 5). Alguns bairros citados são considerados de padrão socioeconômico mais baixo como "Anjo da Guarda", "Coroadinho", "Vila Embratel", "São Raimundo" e "Liberdade"; mas, há também os que podem ser declarados de classe média como "Turu", "São Francisco", "COHATRAC" e "Vinhais".

Mesmo com tal heterogeneidade na escala intraurbana, que denotaria não ter um padrão específico, demonstra, entretanto, que há uma padronização quanto aos principais bairros citados, visto que sua maioria são considerados de classe baixa; àqueles bairros avaliados como classe média cabe ressaltar que no entorno destes têm ocupações irregulares que podem ser um motivo pelo qual aparecem os dados. Considera-se ainda que há a pulverização da violência contra as mulheres nos bairros de São Luís, que se alastra por todas as classes sociais. 

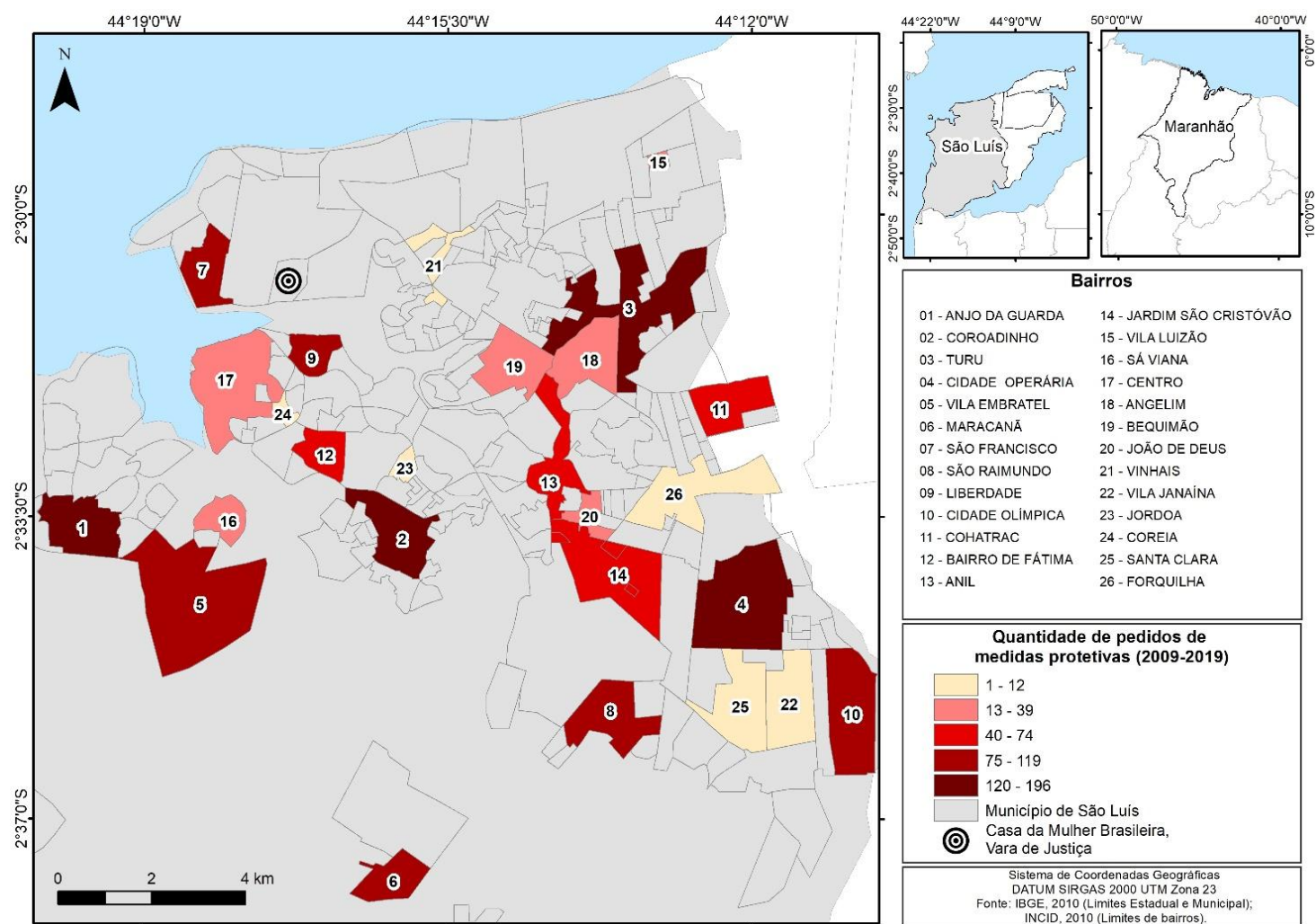

Figura 5: Espacialização da violência segundo os pedidos de medidas protetivas. Fonte: Elaborado pelas autoras.

Cabe recordar que os dados aqui analisados, referente às "Pesquisas Sociais", tiveram como fonte primária os Boletins de Ocorrência da Delegacia da Mulher e outras delegacias, denúncias originadas da Defensoria Pública, do Ministério Público e entre outros, que estão distribuídos de forma aleatória pela cidade. Na Figura 5 é possível observar a localização da Casa da Mulher Brasileira, inaugurada em novembro de 2017 no bairro Jaracaty, dois meses depois da criação da $2^{\mathrm{a}}$ V.D.F.M., que lá se instalou. Importante destacar que a $1^{\text {a }}$ V.D.F.M., criada em 2008 e responsável pelos primeiros dados referentes a 2009, funciona no Fórum Desembargador Sarney Costa, também no bairro Jaracaty, situado nas proximidades da Casa da Mulher Brasileira, demonstrando a dificuldade de acesso das mulheres residentes de bairros periféricos aos órgãos de justiça.

Algumas ponderações são necessárias para analisar a distribuição espacial das medidas protetivas. Primeiro, pode significar que a violência em si, já existia; e com trabalhos de divulgação dos órgãos, instituições e a mídia, intensificou-se o combate à violência. As ações de cunho socioeducativo, com a divulgação da Lei "Maria da Penha", bem como o esclarecimento dos tipos de violência contra a mulher e sua criminalização pode ter encorajado a um maior número de mulheres a formalizar denúncias e romper com as situações de violências.

A criação das $1^{a}$ e $2^{a}$ V.D.F.M. direcionou e incentivou os registros e as emissões das medidas protetivas, juntamente com Casa da Mulher Brasileira que passou a agregar todos os serviços de proteção e acolhimento às mulheres em situação de violência, mesmo que esses órgãos não sejam tão centralizados, geograficamente falando, para que as mulheres tenham mais fácil acesso. Em geral, os deslocamentos até os supracitados órgãos, podem representar o uso de dois transportes públicos, um elemento a ser analisado quanto ao acesso facilitador ou não para as mulheres em situação de violência e em busca de auxílio estatal. Pressupomos ainda que haja muita subnotificação dos casos violentos, perceptíveis pela falta de dados em vários bairros de São Luís, contemplados pela cor cinza (Figura 5), portanto, a violência é bem maior do que está representada cartograficamente.

\section{Considerações finais}

A violência de gênero observado através dos 10 anos da "Pesquisa Social", em São Luís- MA, corrobora com o contexto sociocultural brasileiro que aponta um perfil feminino que reconhece as faces da violência a qual foi e é exposta e que, não mais suportando tal condição, busca auxílio legal, superando o medo de retaliações (MESQUITA, 2010; CALDEIRA, 2012). Foi observado que a distribuição espacial da violência contra a mulher é heterogênea entre os espaços intraurbanos da capital maranhense, revelando até certa 
desigualdade social, pois algumas medidas protetivas foram concedidas para proteger mulher que habitam bairros pobres e periféricos, mas, isso não quer dizer que a violência não esteja nos bairros com população de maior renda.

Quanto ao perfil da mulher vítima de violência, compreende-se ser solteira, jovem e adulta, com idades que variam entre 26 e 43 anos, mãe de um ou mais filhos, sem renda fixa e sem trabalho assalariado. Quanto ao perfil do agressor, o grupo solteiro é majoritário, compreendido na faixa etária de 26 a 34 anos, estabelecido nas profissões mais citadas de motorista, pedreiro, auxiliar de pedreiro, autônomos, vigilantes, mecânicos e estudantes; em sua maioria, no momento do ato violento, até o ano 2014, o agressor fez uso de álcool e entorpecentes e, a partir de 2015, a maioria não estava sob efeito de bebidas alcoólicas e de drogas.

Mesmo com o crescimento do acesso aos serviços especializados de denúncia e proteção às vítimas de violência de gênero, consideramos que ainda estão mal distribuídos na cidade. Provavelmente, pode ser um fator impeditivo para que mais mulheres acessem e denunciem os seus agressores. Pelo perfil das vítimas, identificado pelos dados, a dependência emocional, afetiva e/ou econômica do marido ou companheiro pode restringir os deslocamentos pela cidade em busca de proteção ou até expliquem as subnotificações em alguns bairros mais distantes, por exemplo.

Urge assinalar que as medidas protetivas são um meio, mas não um fim para impedir ou até mesmo combater a violência doméstica, pois assim como as mulheres que são acolhidas, o autor da agressão também precisa passar por acolhimento psicológico e social, com vistas à reeducação e compreensão dos malefícios que uma cultura machista e patriarcal leva à relacionamentos abusivos; do contrário, apenas tem-se libertado uma vítima e deixado o agressor livre para construir outras relações violentas. Neste sentido a violência urbana foi aqui revelada, através da espacialização geográfica; e como esse fenômeno incide na vida das mulheres em suas relações com os espaços, no uso da cidade ou do "território usado", permeado pelas construções dos papéis socioculturais de gênero, de raça e etnia, de classe social e outros elementos representativos.

\section{Agradecimentos}

À Fundação de Amparo à Pesquisa e ao Desenvolvimento Científico e Tecnológico do Maranhão FAPEMA.

\section{Referências}

BRASIL. Lei no 11.340, de 7 de agosto de 2006. Cria mecanismos para coibir a violência doméstica e familiar contra a mulher e dá outras providências. Brasília: Senado, 2006. Disponível em: http://www.planalto.gov.br/ccivil_03/_ato2004-2006/2006/lei/111340.htm. Acesso em: 21 jun. 2020.

CAldeIRA, C. T. M. Perfil Psicopatológico de Agressores Conjugais e Fatores de Risco. 2012. 113 f. Dissertação (Mestrado em Psicologia Clínica e da Saúde) - Universidade da Beira Interior. Portugal: UBI, 2012. Disponível em: https://ubibliorum.ubi.pt/bitstream/10400.6/3891/1/Disserta\%C3\%A7\%C3\%A3o.pdf. Acesso em: 21 jun. 2020.

CARvalho, N. M. C. Perfil Psicológico das Mulheres Vítimas de Violência Doméstica e suas Repercussões. 2010. 69 f. Dissertação (Mestrado em Psicologia Forense e da Transgressão) - Cooperativa de Ensino Superior Politécnico e Universitário. Portugal: CESPU, 2010. Disponível em: https://repositorio.cespu.pt/handle/20.500.11816/67. Acesso em: 21 jun. 2020.

COLOMBARA, M.; PELIZZARI, V. Violencia Doméstica: ¿cuestión privada o pública? - su estado em América Latina. In: Primeras Jornadas Latinoamericanas de Género y Geografia. Buenos Aires: Universidad de Lomas de Zamora, 1999.

CODING RIGHTS; INTERNETLAB. Violências contra mulher na internet: diagnóstico, soluções e desafios. Contribuição conjunta do Brasil para a relatoria especial da ONU sobre violência contra a mulher. São Paulo: CODING RIGHTS; INTERNETLAB, 2017.

DATAFOLHA; FBSP. A Vitimização de Mulheres no Brasil. 2.ed. São Paulo: FBSP, 2019.

DATASENADO. Violência Doméstica e Familiar contra a mulher. Brasília: Secretaria de Transparência; Senado Federal, 2015. 
DATASENADO. Boletim Mulheres e seus Temas Emergentes. Brasília: Senado Federal, 2020.

D'OLIVEIRA, A. F. P. L. et al. Fatores associados à violência por parceiro íntimo em mulheres brasileiras. Rev. Saúde Pública, São Paulo, v. 43, n. 2, p. 299-311, mar./abr. 2009.

GIL, A. C. Como elaborar projetos de pesquisa. 6. Ed. São Paulo: Atlas, 2019.

GOHN, M. G. Mulheres-Atrizes dos Movimentos Sociais: relações político-culturais e debate teórico no processo democrático. Ver. Política \& Sociedade, Florianópolis, v. 6, n. 11, p. 41-70, out. 2007.

IPEA. Retrato das Desigualdades de Gênero e Raça: 20 anos. Brasília: IPEA; Onu Mulheres, 2017.

KOSÍK, K. Dialética do concreto. São Paulo: Editora Paz e Terra, 1995.

KONDER, L. O que é dialética. São Paulo: Brasiliense, 2008.

LABRONICI, L. M. et al. Perfil da violência contra as mulheres atendidas na Pousada de Maria. Rev. da Escola de Enfermagem da USP, São Paulo, v. 44, n. 1, mar. 2010.

LISBOA, M. et al. Custos Sociais e Económicos da Violência Contra as Mulheres: síntese dos resultados do inquérito nacional de 2002. Lisboa: Universidade Nova de Lisboa, 2003.

MESQUITA, A. P. As Marias que Não Calam: perfil das mulheres vítimas de violência após a implementação da lei Maria da Penha em Maceió/AL. In: Seminário Internacional Fazendo Gênero, 9., 2010, Santa Catarina. Anais [...]. Santa Catarina: UFSC, 2010.

DE MOREIRA, R. A Geografia serve para desvendar máscaras sociais. In: DE MOREIRA, R. (org.). Geografia: Teoria e Crítica: o saber posto em questão. Rio de Janeiro: Editora Vozes, 1982.

MOURA, M. A. V.; NETTO, L. A., SOUZA, M. H. N. Perfil sociodemográfico de mulheres em situação de violência assistidas nas delegacias especializadas. In: Esc. Anna Nery, Rio de Janeiro, v.16, n.3, set. 2012.

PASTANA, D. R. Cultura do medo e Democracia: um paradoxo brasileiro. In: Ver. Mediações Londrina, Londrina, v. 10, n. 2, p. 183-198, jul./dez. 2005.

ROSE, G. Feminism and Geography: the limits of geographical knowledge. Cambridge: Polity Press, 1993.

SAFFIOTI, H. A Mulher na Sociedade de Classes: mito e realidade. 3. Ed. São Paulo: Expressão Popular, 2013.

SANTOS, M. A Natureza do Espaço: técnica e tempo, razão e emoção. 4. Ed. São Paulo: Editora da Universidade de São Paulo, 2017.

SILVA, J. M. Um ensaio sobre a potencialidade do uso do conceito de gênero na análise geográfica. In: Rev. de História Regional, Ponta Grossa, n. 8, v. 1, p. 31-45, dez./fev. 2003.

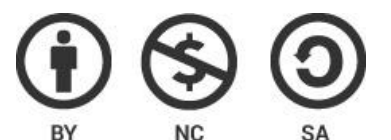

Este artigo é distribuído nos termos e condições do Creative Commons Attributions/AtribuiçãoNãoComercial-CompartilhaIgual (CC BY-NC-SA). 